\title{
UMA TENTATIVA DE ORGANIZAÇÃO SEQÜENCIAL DO CONTEÚDO DA DISCIPLINA QUÍMICA GERAL COM BASE NA TEORIA DE APRENDIZAGEM DE DAVID AUSUBEL
}

Régia Maria Avancini Blanch*

PRESSUPOSTOS GERAIS

$\mathrm{O}$ que se tem visto e sentido nos encontros nacionais de ensino de Química, nos vários trabalhos publicados sobre esse tema e nos depoimentos de colegas atuantes nessa área de conhecimento, são opiniões unânimes sobre a ineficiência deste ensino como se apresenta atualmente.

Este tem sido considerado como um ensino estéril, totalmente desvinculado da vida do estudante e causador de apenas uma armazenagem arbitrária de conhecimentos.

Acredita-se, portanto, que novas alternativas e direcionamentos para este ensino devam ser propostos, na tentativa de modificar esse quadro e, quiçá, revertê-lo.

* Graduada e pós-graduada (lato sensu) em Metodologia do Ensino Área de Concentração - Química pela FCMS, leciona no CESUP, Campo Grande-MS e cursa o programa de Mestrado em Educação na UCDB. 
Isto pode ser alcançado não apenas através do aprimoramento dos procedimentos de ensino, buscando uma otimização das condições externas, mas, também, buscando conhecer a natureza e o mecanismo pelo qual se dá a aprendizagem, ou seja, de como o aluno aprende e do aprofundamento do significado e objetivo da aprendizagem.

Para se buscar este tipo de melhoria de ensino, levando-se em conta também as características do aprendiz, a natureza da aprendizagem e de como este aprende, faz-se necessário ter conhecimento das abordagens a respeito do mecanismo pelo qual a aprendizagem se estabelece.

De modo geral, podem-se distinguir três grandes enfoques teóricos na concepção da natureza do processo ensino-aprendizagem: o empirismo comportamentalista, $o$ apriorístico e o cognitivismo.

O empirismo explica que o conhecimento acontece a partir de impressões do mundo externo em nossos órgãos do sentido; vemos, ouvimos, tateamos e só por isso conhecemos. É a teoria da associação entre estímuloresposta que constitui a explicação própria do empirismo. Vale a máxima aristotélica "nada está no intelecto que não tenha passado pelos sentidos".

$\mathrm{O}$ apriorismo concebe o conhecimento pelo inatismo, isto é, toda pessoa, ao nascer, já traz algo programado na bagagem hereditária que irá amadurecendo, despertando, gradualmente, em etapas previstas.

O cognitivismo enfatiza o processo da cognição pela ação do sujeito que aprende. Através da ação individual 
é que o universo de significados (conceitos) do indivíduo tem origem, à medida que o ser se situa no mundo, estabelece relações de significação, isto é, atribui significados à realidade e elabora conceitos, generalizações, proposições. Este enfoque preocupa-se com o processo de compreensão, transformação, armazenamento e uso da informação envolvida na cognição e procura identificar regularidades nesse processo. Ocupa-se, pois, particularmente dos processos mentais envolvidos na aprendizagem, enfatizando a ação do sujeito que conhece, que aprende. Uma das teorias cognitivistas, a de David Ausubel (1968), é proposta neste trabalho como referência para a organização do conteúdo de Química Geral para cursos introdutórios desta disciplina.

\section{BREVE ENFOQUE SOBRE A TEORIA DE DAVID AUSUBEL}

\subsection{Aprendizagem Significativa}

A teoria de David Ausubel focaliza, primordialmente, a aprendizagem cognitiva.

Ausubel (1968) é representante do cognitivismo e, portanto, propõe uma explicação teórica do processo de aprendizagem segundo o ponto de vista cognitivista de elaboração do próprio conhecimento pelo aprendiz, embora conheça a importância da experiência afetiva. Para ele o principal fator que influencia a aprendizagem é a estrutura cognitiva presente no indivíduo, portanto, se a estrutura cognitiva de um aluno for clara e organizada adequadamente, 
a aprendizagem e a retenção de um assunto novo é facilitada; se ela é instável, ambígüa e desorganizada, a aprendizagem fica prejudicada.

Sendo assim, professores e educadores devem considerar, durante o processo ensino-aprendizagem, a quantidade, a clareza e a organização do conhecimento presente no aprendiz.

"A estrutura cognitiva para o ser humano, tal como a propõe Ausubel, é hierarquicamente organizada, ou seja, conceitos e proposições mais inclusivos, com maior poder de generalização, estão no topo da hierarquia e abrangem conceitos e proposições menos inclusivos, menor poder de generalização" (Ausubel, 1968).

Perguntado sobre qual o fator mais importante na aprendizagem, Ausubel responde que é a estrutura cognitiva do aluno.

O mesmo fato ocorre, também, com as disciplinas estudadas pelos alunos em todos os níveis. Estas consistem num conjunto de conceitos hierarquicamente organizados (estrutura cognitiva da matéria de ensino) e o papel do professor é identificar, em cada disciplina, os conceitos mais abrangentes que tenham o maior poder de inclusividade e que sejam mais amplos, para facilitar a sua aprendizagem pelos alunos.

Para Ausubel é importante, também, que o professor auxilie o aluno na aquisição de aprendizagem significativa (Novak, 1981) que é definida por ele como sendo um processo através do qual uma nova informação relaciona-se 
com um aspecto relevante da estrutura do conhecimento do indivíduo, ou seja, este processo envolve a interação da nova informação com uma estrutura do conhecimento específico, a qual Ausubel define como conceitos subsunçores existentes na estrutura cognitiva do indivíduo.

Em Química, por exemplo, se os conceitos de matéria e substâncias já existem na estrutura cognitiva do aluno, eles servirão de subsunçores para novas informações referentes a certos tipos de substâncias como, por exemplo, sais, óxidos, polímeros, gorduras, ácidos, etc. Este processo de "ancoragem" da nova informação modifica o conceito subsunçor, ou seja, aperfeiçoa-o. Sendo assim, de acordo com a frequêencia com que ocorre a aprendizagem significativa, os subsunçores apresentamse de forma bem desenvolvida ou limitados e/ou pouco desenvolvidos. No exemplo dado, uma idéia intuitiva de substância serviria como subsunçor para novas informações referentes a vários tipos de substâncias como açúcares, óleos, ácidos, óxidos, etc., e à medida que esses novos conceitos fossem aprendidos, significativamente, os conceitos subsunçores iniciais seriam aperfeiçoados.

Se a aprendizagem ocorrer sem associação aos conceitos relevantes existentes na estrutura cognitiva do aprendiz, ou seja, sem atribuição de significados pessoais (idiossincrasia) ela é chamada por Ausubel de mecânica e é caracterizada por uma armazenagem arbitrária, sem interação entre a nova informação e aquela já existente, provocando uma armazenagem desconexa para o aprendiz, pois não ocorre a ligação com conceitos subsunçores específicos.

Porém, para Ausubel uma certa dose de aprendiza- 
gem mecânica é sempre necessária quando um indivíduo adquire informação em uma área de conhecimento completamente nova para ele, ou seja, a aprendizagem mecânica ocorrerá até que algumas informações referentes a essa área de conhecimento se configurem como subsunçores, ainda que pouco elaborados, pois, posteriormente, com a ocorrência de aprendizagem significativa estes poderão ser aperfeiçoados.

Em crianças, com idade escolar, a aprendizagem significativa ocorre, pois estas já possuem um conjunto de conceitos que foram adquiridos, quando pequenos, através do processo denominado formação de conceitos, que envolve aquisição espontânea e indutiva de idéias genéricas.

A partir daí novos conceitos ainda podem ser formados; no entanto a maioria deles é adquirida através de assimilação, diferenciação progressiva e reconciliação integrativa (Novak, 1981).

a) Assimilação

A assimilação ou ancoragem é um processo que ocorre quando um conceito ou proposição, potencialmente significativo, é assimilado a uma idéia ou conceito mais inclusivo já existente na estrutura cognitiva, sendo que ambos, nova informação e conceito subsunçor, são modificados pela interação.

b) Diferenciação Progressiva e Reconciliação Integrativa

Segundo Ausubel, quando ocorre aprendizagem significativa os conceitos são desenvolvidos, elaborados e 
diferenciados em conseqüência das interações que ocorrem entre as novas informações e as já existentes na estrutura cognitiva.

Do ponto de vista ausubeliano, o desenvolvimento de conceitos é facilitado quando os elementos mais inclusivos de um conceito são introduzidos em primeiro lugar e, posteriormente, então, esse conceito é progressivamente diferenciado. Este é o princípio da diferenciação progressiva.

Para Ausubel, a aquisição de aprendizagem significativa será facilitada se forem assimilados inicialmente as idéias mais gerais e inclusivas de determinado assunto para, posteriormente, serem progressivamente diferenciados em termos de detalhe e especificidade. Para ele os aspectos diferenciados de um todo mais inclusivo é mais facilmente captado do que o entendimento do todo a partir de suas partes diferenciadas e a organização do conceito de uma certa disciplina na mente de um indivíduo é uma estrutura hierárquica, na qual as idéias mais inclusivas estão no topo da estrutura e, progressivamente, incorporam proposições, conceitos e fatos menos inclusivos e mais diferenciados.

Portanto, o princípio de diferenciação progressiva deve ser levado em conta ao programar o conteúdo de uma disciplina, ou seja, as idéias mais gerais e mais inclusivas da disciplina devem ser apresentadas no início para depois serem, progressivamente, diferenciadas.

Ausubel também propõe como importante na programação do conteúdo a exploração explícita de relações entre proposições e conceitos, das diferenças e similaridades importantes e da reconciliação de inconsistências 
reais ou aparentes. Isso deve ser feito para atingir-se o que ele chama de reconciliação integrativa.

Para esta ser conseguida o conteúdo deve ser ensinado, começando-se com os conceitos mais gerais, ilustrando-se como os conceitos subordinados estão a eles relacionados e, então, voltando-se, através de exemplos, a novos significados para os conceitos mais inclusivos.

\subsection{Mapas Conceituais}

O mapeamento conceitual, baseado na teoria cognitiva de David Ausubel é visto como um diagrama de significados, de relações significativas entre conceitos. Este diagrama pode apresentar uma certa organização hierárquica, porém não é um simples organograma ou diagrama de fluxo, não implica temporalidade ou direcionalidade, nem hierarquias organizacionais ou de poder. Implica, sim, relações entre conceitos (Ronca, 1978).

Estes podem ser construídos utilizando-se figuras geométricas ou outro tipo de figuras e linhas (Fig. 1). A forma $\mathrm{e} o$ formato das figuras e das linhas nada significam em um mapa conceitual. O importante é verificar o entendimento das relações existentes entre os conceitos, através das linhas que os unem. Por vezes, setas são utilizadas para dar um sentido de direção às relações conceituais, porém não se constituem uma obrigatoriedade.

Os mapas conceituais podem ser construídos obedecendo a uma hierarquia conceitual ou não, isto é, 


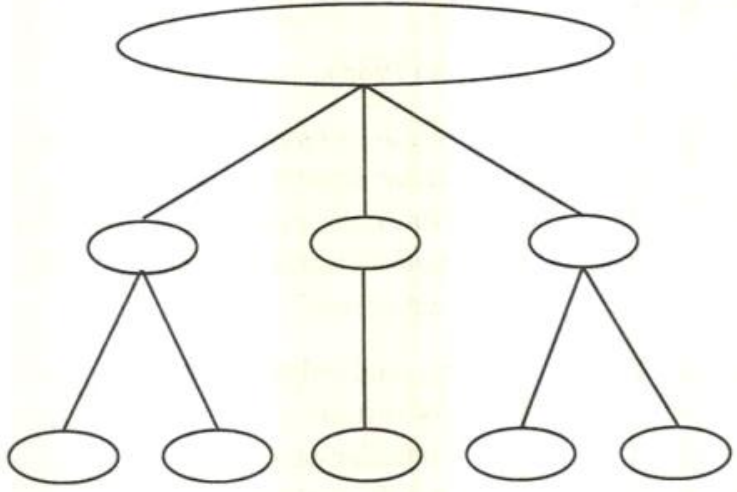

Fig. 1 - Modelo de mapa conceitual segundo a idéia de diferenciação progressiva de David Ausubel.

podem-se ter conceitos organizados de forma tal que no topo da hierarquia se verifiquem os conceitos mais inclusivos e na base os mais específicos, ou estes conceitos podem estar organizados de forma a não seguir nenhuma hierarquização, porém, de alguma forma, relacionados entre si.

Não se pode dizer que existam regras para a construção de mapas conceituais. O que se tem são algumas linhas, segundo as quais pode-se traçar um plano de procedimento para a composição dos mapas que, no entanto, são circunstanciais e servem apenas para uma situação específica. Por exemplo, podem-se estabelecer algumas regras de procedimento para a elaboração de mapas que serão 
utilizados em uma pesquisa ou em uma situação particular de ensino-aprendizagem.

\section{Segundo Moreira (1988), \\ "O importante é que o mapa seja instrumento capaz de evidenciar significados atribuidos a conceitos e relações entre conceitos no contexto de um corpo de conhecimento de uma disciplina, de uma matéria de ensino".}

Então não importa qual o tipo de representação que a pessoa que está construindo o mapa estabelece, o importante é que, ao acomodar os conceitos e relacionálos, o indivíduo seja capaz de explicar que tipo de relação existe entre esses conceitos.

Embora a técnica do mapeamento conceitual tenha como suporte teórico a teoria de David Ausubel, esta nunca foi mencionada em sua obra. Foi desenvolvida em meados da década de setenta por Joseph Novak e colaboradores na Universidade de Cornell, nos EUA.

O ensino baseado na perspectiva ausubeliana é um ensino que visa, primordialmente, à aprendizagem significativa e os mapas conceituais foram desenvolvidos para promover este tipo de aprendizagem. O professor, ao ensinar, tem a intenção de fazer com que o aluno adquira certos significados que são aceitos no contexto da matéria de ensino, e compartilhados por certa comunidade de usuários. $\mathrm{O}$ ensino busca fazer com que o aluno venha também a compartilhar tais significados. Mapas de conceitos podem ser valiosos na consecução desse objetivo podendo, também, fornecer informações sobre como está sendo 
alcançado.

O mapeamento conceitual pode ser usado em várias situações e para diversos fins. Pode ser utilizado como ferramenta didática, recurso de aprendizagem, um recurso de motivação, meio de avaliação e como subsídio para a organização seqüencial do conteúdo.

\section{ORGANIZAÇÃO DO CONTEÚDO DE QUIMICA GERAL COM BASE NA TEORIA DE AUSUBEL}

Usualmente, se encontra nos livros textos e na prática docente dos cursos introdutórios de Química Geral uma organização seqüencial do conteúdo do mais específico para o mais geral. Inicia-se o estudo pela microestrutura da matéria (tipos de átomos, número atômico, número de massa, orbitais, spins, ligações químicas, interações intermoleculares, etc.) para somente no final do curso estudar os tipos de substâncias e suas propriedades. Esta seqüência é vista separadamente e ocorre nenhuma ou pouca integração entre os assuntos.

Analisando-se esta organização seqüencial se pode afirmar que, de certo modo, ela se apresenta como oposta a uma seqüência ausubeliana, pois inicia da microestrutura para a macroestrutura, enquanto que Ausubel defende a posição de que as idéias, fenômenos e conceitos mais gerais e inclusivos devem ser apresentados no início do curso, para que sirvam de "ancoradouro" conceitual para a aprendizagem subseqüente.

A figura 2 representa uma tentativa de organização 
seqüencial do conteúdo de Química Geral para cursos introdutórios através de um mapa conceitual, de acordo com a teoria de aprendizagem de David Ausubel. Nesta organização foi tentado seguir o princípio da diferenciação progressiva proposto por Ausubel, ou seja, iniciou-se pelas idéias mais gerais e inclusivas da disciplina que, progressivamente, foram sendo diferenciadas.

O conteúdo inicia, de maneira geral, discutindo a natureza da matéria, as teorias antigas sobre a constituição da matéria (continuidade ou des-continuidade), sobre como se deu a evolução das idéias relativas às transformações da matéria, a evolução da ciência química e a ênfase nos conceitos mais gerais como o de substâncias e a introdução sobre as representações das substâncias (símbolos químicos).

Na segunda unidade já se especifica um pouco mais o conceito de substância (substância pura e mistura), no entanto, ela também é geral porque trata de uma primeira diferenciação entre as substâncias, enfatizando os conceitos de substância pura e mistura em si e não uma instância particular dos mesmos.

A próxima unidade, seguindo o princípio da diferenciação progressiva, é mais específica do que a anterior, porque trata apenas dos tipos de misturas e os processos físicos de separação e purificação das mesmas, podendo servir de ponto de partida, posteriormente, para o estado da química analítica, fornecendo uma visão geral e funcionando como uma espécie de organizador prévio para esta disciplina.

Em seguida, num mesmo nível de diferenciação, o 


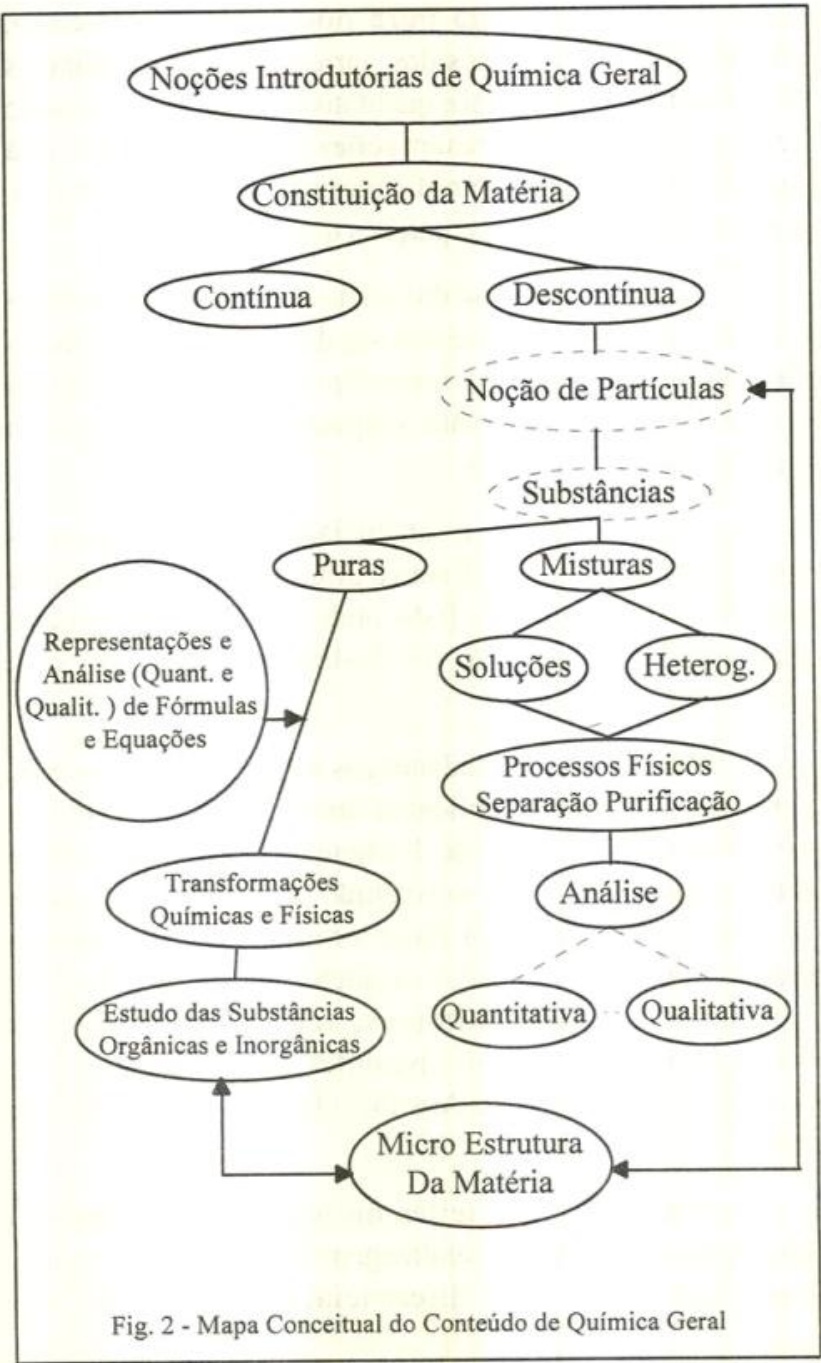


conceito de substância pura pode ser especificado, introduzindo os conceitos dos vários tipos de substâncias de um ponto de vista geral e qualitativo. Nessa etapa deverão ser reforçadas as representações qualitativas de uma substância e poderá ser introduzida uma análise quantitativa, também, das fórmulas e equações químicas.

Feito isso, pode-se dar início ao estudo das transformações químicas, diferenciando-as das físicas, aproveitando para se demonstrarem os vários tipos de reações químicas existentes, explorando tanto o aspecto qualitativo quanto o quantitativo das equações.

Nesta etapa, pode ser iniciado o estudo das substâncias de maneira global, sem a diferenciação inicial entre orgânicas e inorgânicas (isto pode ser feito de maneira gradual à medida que se for ilustrando o conteúdo com exemplos).

Muitas das propriedades das substâncias, nessa fase, somente poderão ser explicadas através de noções sobre a microestrutura da matéria. Portanto, continuando com a diferenciação progressiva do estudo das substâncias, podese iniciar a explanação da microestrutura da matéria (constituída de partículas), a evolução das teorias atômicas, o átomo, ligações químicas, tentando reconciliar inconsistências reais ou aparentes entre os conceitos, buscando alcançar o que Ausubel chama de reconciliação integrativa.

Desta maneira, se tentou organizar o conteúdo, procurando facilitar a aprendizagem significativa do aluno, buscando promover a diferenciação progressiva e a 
reconciliação integrativa dos conceitos e proposições de um curso introdutório de química geral.

\section{CONSIDERAÇÕES FINAIS}

Este trabalho não pretendeu, de forma alguma, ser conclusivo, até porque não se percebe que o mesmo tenha atingido resultados satisfatórios quanto ao que se aspira em relação à mudança curricular para cursos introdutórios de química geral.

Os conteúdos foram organizados de forma a se tentar um ensino baseado na diferenciação progressiva e reconciliação integrativa propostas por Ausubel; no entanto, ainda se verificam algumas dificuldades para se explicar a noção de substâncias e transformações químicas, sem se recorrer, de início, à microestrutura da matéria. Tentativas têm sido feitas no sentido de superá-las. Acredita-se que isto se dê, principalmente, em conseqüência do condicionamento que esta professora e alunos experimentam em conseqüência de terem se acostumado a refletir esta ciência a partir da micro-estrutura, e não o contrário; no caso dos alunos, apesar de estarem em cursos introdutórios, já apresentam noções de Química nas quais a microestrutura foi enfatizada.

Feitas essas considerações, espera-se que este trabalho venha, de alguma forma, se não proporcionar, trazer benefícios diretos àqueles que comungam com este tipo de pensamento, ao menos ressaltar o assunto ou, quem sabe, incitar reflexões sobre ele. 


\section{REFERÊNCIAS BIBLIOGRÁFICAS}

AUSUBEL, D. P. Educacional psychology, a congnitive view. NY : Holt, Rinehart \& Winston, 1968.

AUSUBEL, D.P., NOVAK, J.D.e HANESIAN, H.Psicologia educacional. Rio de Janeiro : Interamericana, 1980.

MOREIRA, Marco A. O ensino. Mapas conceituais e aprendizagem significativa. n²3, 87-95, 1988.

NOVAK, J. D. Uma teoria de educação. São Paulo: Editora Pioneira, 1981 .

RONCA, A. C. C. O Modelo de Ensino de David Ausubel, In: MILAN, Josefina. Psicologia, São Paulo : Papelivros, 1978. 